\title{
Article \\ Complications and Discharge after Radical Cystectomy for Older Patients with Muscle-Invasive Bladder Cancer: The ELCAPA-27 Cohort Study
}

\author{
Romain Geiss ${ }^{1}$, Lucrezia Sebaste ${ }^{1}$, Rémi Valter ${ }^{2}$, Johanne Poisson ${ }^{1,3}$, Soraya Mebarki ${ }^{1}$, Catherine Conti ${ }^{1}$, \\ Dimitri Vordos ${ }^{4}$, Michael Bringuier ${ }^{5}$, Arnaud Méjean ${ }^{6}$, Pierre Mongiat-Artus ${ }^{7}$, Tristan Cudennec ${ }^{8}$, \\ Florence Canoui-Poitrine ${ }^{2,9}$, Philippe Caillet ${ }^{1,9}$ and Elena Paillaud ${ }^{1,9,10, * \text { iD }}$
}

Citation: Geiss, R.; Sebaste, L.; Valter, R.; Poisson, J.; Mebarki, S.; Conti, C.; Vordos, D.; Bringuier, M.; Méjean, A.; Mongiat-Artus, P.; et al. Complications and Discharge after Radical Cystectomy for Older Patients with Muscle-Invasive Bladder Cancer: The ELCAPA-27 Cohort Study. Cancers 2021, 13, 6010. https://doi.org/10.3390/ cancers 13236010

Academic Editor: Daniel S. Sitar

Received: 25 October 2021

Accepted: 25 November 2021

Published: 29 November 2021

Publisher's Note: MDPI stays neutral with regard to jurisdictional claims in published maps and institutional affiliations.

Copyright: (c) 2021 by the authors. Licensee MDPI, Basel, Switzerland. This article is an open access article distributed under the terms and conditions of the Creative Commons Attribution (CC BY) license (https:// creativecommons.org/licenses/by/ $4.0 /)$.
1 Department of Geriatrics, AP-HP, Hôpital Européen Georges Pompidou, 75015 Paris, France; romain.geiss@aphp.fr (R.G.); lucreziasebaste@hotmail.it (L.S.); johanne.poisson@aphp.fr (J.P.); soraya.mebarki@aphp.fr (S.M.); catherine.conti@aphp.fr (C.C.); philippe.caillet@aphp.fr (P.C.)

2 Department of Public Health, AP-HP, Hôpital Henri-Mondor, 94000 Créteil, France; remi.valter@aphp.fr (R.V.); florence.canoui-poitrine@aphp.fr (F.C.-P.)

3 Center for Research on Inflammation, Université de Paris, Inserm U1149, 75018 Paris, France

4 Department of Urology, AP-HP, Hôpital Henri-Mondor, 94000 Créteil, France; dimitri.vordos@hmn.aphp.fr

5 Department of Supportive Care and Medical Oncology, Institut Curie, 92210 Saint-Cloud, France; michael.bringuier@curie.fr

6 Department of Urology, AP-HP, Hôpital Européen Georges Pompidou, 75015 Paris, France; arnaud.mejean@aphp.fr

7 Department of Urology, AP-HP, Hôpital Saint Louis, 75010 Paris, France; pierre.mongiat-artus@aphp.fr

8 Department of Geriatrics, AP-HP, Hôpital Ambroise-Paré, 92100 Boulogne-Billancourt, France; tristan.cudennec@aphp.fr

9 Université Paris-Est, Inserm, IMRB, 94000 Créteil, France

10 Faculty of Health, Université de Paris, 75006 Paris, France

* Correspondence: elena.paillaud@aphp.fr; Tel.: +33-156092-709

Simple Summary: Radical cystectomy is associated in older patients with an increased risk of postoperative complications. However, these studies did not take into account geriatric variables. In our study, all patients had a standardized geriatric assessment prior to radical cystectomy. Although geriatric variables were not associated with 30-day complications, our study found that frailty (measured as a G8 score $\leq 14$ ), a loss of autonomy, anemia, and severe comorbidities were associated with a higher risk of not being discharged home at one month after the surgery.

Abstract: Radical cystectomy is the standard of care for localized bladder cancer but is associated with high morbidity and mortality rates-especially among older patients with comorbidities. The association between geriatric assessment parameters on post-operative complications and discharge has not previously been investigated. The present analysis of the Elderly Cancer Patient (ELCAPA) prospective cohort included all patients aged $\geq 70$ having undergone a geriatric assessment and then radical cystectomy for localized muscle-invasive bladder cancer between 2007 and 2018. The primary endpoint was the proportion of patients with one or more complications in the first 30 days after cystectomy. The secondary endpoints were the length of hospital stay (LOS), the 30-day mortality, and discharge rates. Sixty-two patients (median age: 81 ; range: 79-83.8) were included. The 30 -day complication rate was $73 \%$, and $49 \%$ of the patients had experienced a major complication, according to the Clavien-Dindo classification. The 30 -day mortality rate was $4 \%$. None of the geriatric, oncological, or laboratory parameters were significantly associated with the occurrence or severity of complications. The median (interquartile range) LOS was 18 days (15-23) overall and was longer in patients with complications (19 days vs. 15 days in those without complications; $p=0.013$ ). Thirty days after cystectomy, 25 patients (53\%) had been discharged to home and $22(47 \%)$ were still in a rehabilitation unit. In a univariate analysis, a Geriatric- 8 score $\leq 14$, a loss of one point on the Activities of Daily Living Scale, anemia, at least one grade $\geq 3$ comorbidity on the Cumulative Illness Rating Scale-Geriatric, and an inpatient geriatric assessment were associated with a risk of not being 
discharged to home. In older patients having undergone a geriatric assessment, radical cystectomy is associated with a high complication rate, a longer LOS, and functional decline at 30 days.

Keywords: radical cystectomy; geriatric assessment; older patient; complications; length of hospital stay; functional decline; discharge

\section{Introduction}

Bladder cancer is a disease of older people; the median age at diagnosis is 73 [1]. Radical cystectomy $(\mathrm{RC})$ with or without perioperative chemotherapy constitutes the standard of care for localized, muscle-invasive bladder cancer [2]. Even though the frequency of $\mathrm{RC}$ has increased over recent years, patients aged 80 or over are less likely to receive this treatment than their younger counterparts (20\% vs. $55 \%$, respectively) [3]. Indeed, RC is a major surgical procedure with high morbidity and mortality rates, which increase with age [4]. For example, mortality rates as high as $10 \%$ have been reported for patients in their $80 \mathrm{~s}[5]$.

Considering that smoking is the main risk factor for bladder cancer, patients often have smoking-related cardiovascular and respiratory comorbidities. The median number of chronic comorbidities is eight for patients with bladder cancer, compared with four in non-cancer patients [6]. The comorbidity burden (evaluated with the Charlson Comorbidity Index or the American Society of Anesthesiology (ASA) score, for example) is also associated with higher morbidity and mortality rates following RC [7]. Furthermore, several studies have shown that frailty (measured with various tools, such as the modified frailty index (mFI)), is an independent risk factor for adverse events following RC [8].

A geriatric assessment (GA) is a multidimensional evaluation of different domains: functional status (including the fall risk), nutrition, cognitive status, mood, comorbidities, polypharmacy, sensory impairments, and social support. A GA is recommended by the International Society of Geriatric Oncology [9] and the American Society of Clinical Oncology [10] for patients at risk of frailty (as identified with screening tools like the Geriatric-8 (G8) and the Vulnerable Elders Survey (VES-13)) prior to deciding on the cancer treatment. Although the GA's domain scores predict postoperative outcomes in oncology in general, specific data for RC are lacking.

The objectives of the present study were to assess the 30-day complication rate; the 30-day mortality rate; the length of hospital stay (LOS); the 30-day discharge rate; and the prognostic value of the GA scores, oncologic variables, and routine blood test results.

\section{Materials and Methods}

\subsection{Study Design}

ELCAPA is a prospective, multicenter study of a cohort of patients aged 70 and over with a solid tumor cancer and who have been referred to a geriatric oncology clinic for a GA prior to selection of a cancer treatment in 19 hospitals in the greater Paris region of France. The ELCAPA cohort's GA has been described previously [11]. All patients provided their written informed consent prior to inclusion. The ELCAPA study protocol has been approved by an institutional review board (CPP Ile-de-France I, Paris, France; reference: 2019 mai-MS121). ELCAPA cohort is registered on ClinicalTrials.gov (NCT02884375).

In the present analysis (ELCAPA-27), we included all ELCAPA patients with a localized muscle-invasive bladder cancer treated with RC between 2007 and 2018 at seven of the 19 hospitals (Henri-Mondor, Hôpital Europeéen Georges Pompidou, Cochin, Saint-Louis, Paul-Brousse, Bretonneau, and Institut Curie).

The non-inclusion criteria were metastatic cancer, no RC, non-invasive bladder cancer, a second cancer (i.e., in addition to bladder cancer), and the lack of data on postoperative follow-up (Figure 1). 


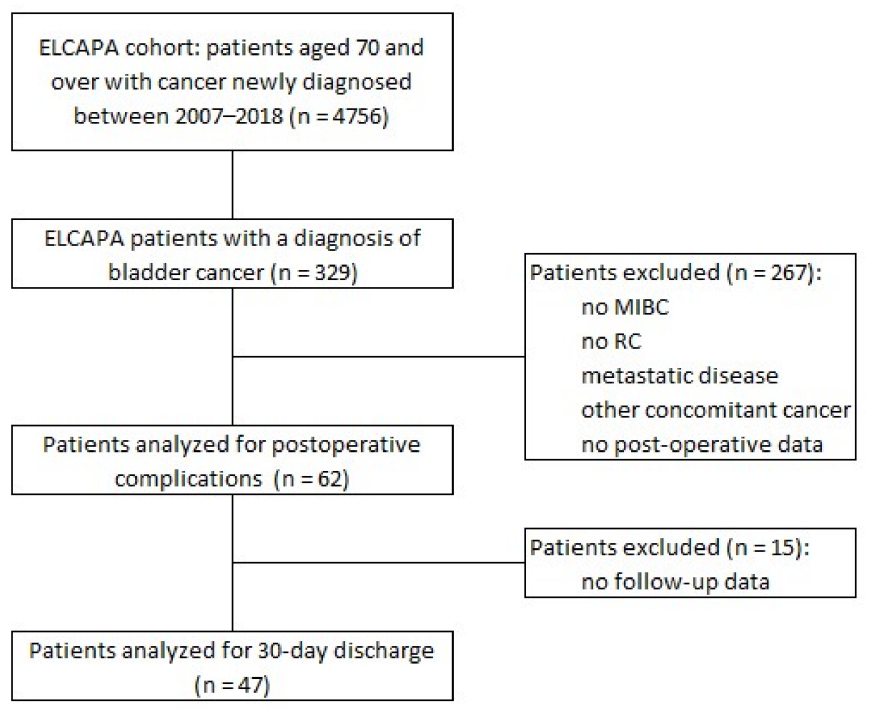

Figure 1. Flow diagram of participants. MIBC: muscle-invasive bladder cancer; RC: radical cystectomy.

\subsection{Data Collection}

We prospectively collected data on the patients' general and geriatric characteristics from the GA performed before surgery: age, sex, smoking history, functional status (performance status, a six-item activities of daily living (ADL) score, and an eight-item instrumental activities of daily living (IADL), mobility (falls in the past 6 months, a timed up-and-go (TUG) test, and the one-leg standing balance test), nutritional status (weight loss $\geq 5 \%$ in the previous month and/or $\geq 10 \%$ in the previous 6 months, body mass index, the Mini Nutritional Assessment score), cognitive status (the Mini-Mental State Examination), mood (the four-item Mini-Geriatric Depression Scale), comorbidities (on the Cumulative Illness Rating Scale-Geriatric (CIRS-G)), polypharmacy (four or more prescription medications), sensory disorders (eyesight and hearing), and the social environment (living alone or not).

The prospectively collected pre-operative laboratory variables were the blood hemoglobin level, the white blood cell count, and the serum creatinine, calcium, and albumin levels. Anemia was defined as a hemoglobin level below $13 \mathrm{~g} / \mathrm{dL}$ for adult males and $12 \mathrm{~g} / \mathrm{dL}$ for adult females, neutrophilic leukocytosis was defined as a neutrophil count above $7.5 \mathrm{G} / \mathrm{L}$, and hypercalcemia was defined as a corrected serum calcium level above $2.6 \mathrm{mmol} / \mathrm{L}$.

The TNM classification was based on the surgical pathology report. Data on neoadjuvant chemotherapy and radiotherapy were collected prospectively. The ASA score and data on the type of urinary diversion were collected retrospectively.

\subsection{Outcomes}

The primary endpoint was the 30-day post-operative complication rate. Complications were defined as surgical complications (bleeding, evisceration, surgical site infection, occlusion, or fistula), non-surgical complications (non-surgical site infection, thromboembolic complications, cardiovascular complications, delirium, falls, bed sores, and other complications), and death. Complications were evaluated according to the Clavien-Dindo classification: grade I and II complications were considered to be minor, and grade III, IV, and $\mathrm{V}$ complications were considered to be major. When a given patient had more than one complication, the most severe Clavien-Dindo grade was considered in the analysis.

The secondary endpoints were the LOS and the 30-day mortality and discharge rates.

\subsection{Statistical Analysis}

The study populations' characteristics were described using summary statistics. We made no assumptions about missing data and expressed proportions with regard to the 
number of patients with data. Categorical variables were described as the frequency (percentage), and continuous variables were described as the mean (standard deviation) or the median (interquartile range), depending on the data distribution. Intergroup differences were assessed using the Wilcoxon rank sum test or the Kruskal-Wallis test for continuous variables and the chi-squared test or Fisher's exact test for categorical variables. KaplanMeier survival curves were plotted using the survival package in R. All tests were two-sided and a $p$ value $<0.05$ was considered significant. All statistical analyses were performed using R software v. 4.0.2 R Foundation for Statistical Computing, Vienna, Austria.

\section{Results}

\subsection{Population Characteristics}

A total of 62 patients having undergone RC were included in the study (Table 1). The median age was 81 (range: 79-83.8). The majority of the patients were male $(77 \%)$ and current or former smokers $(72 \%)$. The tumors were locally advanced: $48 \%$ were graded as $\geq \mathrm{pT} 3$ and $54 \%$ had positive lymph nodes.

Table 1. Characteristics of the study population.

\begin{tabular}{|c|c|}
\hline Patients Characteristics & $n(\%)$ \\
\hline Total & $62(100)$ \\
\hline \multicolumn{2}{|l|}{ Age (years) } \\
\hline Median (IQR) & $81.0(79.0-83.8)$ \\
\hline \multicolumn{2}{|l|}{ Sex } \\
\hline Male & $48(77.4)$ \\
\hline \multicolumn{2}{|l|}{ Consultation } \\
\hline Inpatient & $8(13)$ \\
\hline Outpatient & $54(87)$ \\
\hline \multicolumn{2}{|l|}{ G8 } \\
\hline Median (Min, Max) & $12.5(4.00,16.0)$ \\
\hline$\leq 14$ & $43(69.4)$ \\
\hline$>14$ & $10(16.1)$ \\
\hline Missing & $9(14.5)$ \\
\hline \multicolumn{2}{|l|}{ Social environment } \\
\hline Living alone & $16(26)$ \\
\hline \multicolumn{2}{|l|}{ Functional status } \\
\hline \multicolumn{2}{|l|}{ ECOG-PS } \\
\hline $0-1$ & $50(80.6)$ \\
\hline 2 & $10(16.1)$ \\
\hline $3-4$ & $2(3.3)$ \\
\hline \multicolumn{2}{|l|}{ ADL score } \\
\hline$\leq 5 / 6$ & $8(13)$ \\
\hline \multicolumn{2}{|l|}{ IADL score } \\
\hline$\leq 7 / 8$ & $30(48.4)$ \\
\hline \multicolumn{2}{|l|}{ Tobacco smoking } \\
\hline Current smoker & $6(9.7)$ \\
\hline Former smoker & $37(59.7)$ \\
\hline
\end{tabular}


Table 1. Cont.

\begin{tabular}{|c|c|}
\hline Patients Characteristics & $n(\%)$ \\
\hline Never-smoker & $17(27.4)$ \\
\hline Missing & $2(3.2)$ \\
\hline \multicolumn{2}{|l|}{ Comorbidity } \\
\hline Median CIRS-G (IQR) & $12(8-14)$ \\
\hline$\geq 1$ grade $3-4$, CIRS-G & $31(54)$ \\
\hline \multicolumn{2}{|l|}{ Polypharmacy } \\
\hline$>4$ drugs per day & $38(61.3)$ \\
\hline \multicolumn{2}{|l|}{ Cognitive impairment } \\
\hline MMSE score < 24 & $6(9.7)$ \\
\hline \multicolumn{2}{|l|}{ Depressive disorder } \\
\hline Mini-GDS score $\geq 1$ & $15(24.2)$ \\
\hline \multicolumn{2}{|l|}{ Mobility } \\
\hline Falls in the past 6 months & $13(21)$ \\
\hline Timed up and go test $\leq 20 \mathrm{~s}$ & $51(82)$ \\
\hline One-leg standing balance test $<5 \mathrm{~s}$ & $27(43.5)$ \\
\hline \multicolumn{2}{|l|}{ Sensory impairment } \\
\hline Eyesight & $9(14.5)$ \\
\hline Hearing & $29(46.8)$ \\
\hline \multicolumn{2}{|l|}{ Nutritional status } \\
\hline \multicolumn{2}{|l|}{ Weight loss (\%) } \\
\hline in the last 1 month & $9(14.5)$ \\
\hline in the last 6 months & $17(27.4)$ \\
\hline \multicolumn{2}{|l|}{ Albuminemia (g/L) } \\
\hline Median (IQR) & $35(24-38)$ \\
\hline \multicolumn{2}{|l|}{$\mathrm{BMI}\left(\mathrm{kg} \cdot \mathrm{m}^{2}\right)$} \\
\hline$<21$ & $12(19.3)$ \\
\hline $21-25$ & $17(27.4)$ \\
\hline $25-30$ & $25(40.3)$ \\
\hline$>30$ & $8(13)$ \\
\hline Carcinologic and surgical characteristics & $n(\%)$ \\
\hline \multicolumn{2}{|l|}{ pTNM } \\
\hline \multicolumn{2}{|l|}{$\mathrm{T}$} \\
\hline 0 & $4(7.14)$ \\
\hline 1 & $9(16.1)$ \\
\hline 2 & $8(14.3)$ \\
\hline 3 & $20(35.7)$ \\
\hline 4 & $10(17.9)$ \\
\hline In situ associated & $5(8.93)$ \\
\hline Missing data & 6 \\
\hline
\end{tabular}


Table 1. Cont.

\begin{tabular}{|c|c|}
\hline Patients Characteristics & $n(\%)$ \\
\hline \multicolumn{2}{|l|}{$\mathrm{N}$} \\
\hline 0 & $37(66.1)$ \\
\hline 1 & $6(10.7)$ \\
\hline 2 & $6(10.7)$ \\
\hline 3 & $3(5.36)$ \\
\hline 4 & $0(0)$ \\
\hline $\mathrm{x}$ & $4(7.14)$ \\
\hline Missing data & 6 \\
\hline Neoadjuvant chemotherapy & $3(4.8)$ \\
\hline Preoperative radiotherapy & $1(1.6)$ \\
\hline \multicolumn{2}{|l|}{ Urinary diversion } \\
\hline Bricker (ileal conduit) & $60(96.8)$ \\
\hline Bilateral cutaneous ureterostomy & $1(1.6)$ \\
\hline Neobladder & $1(1.6)$ \\
\hline \multicolumn{2}{|l|}{ ASA score } \\
\hline Median (IQR) & $3(2-3)$ \\
\hline \multicolumn{2}{|l|}{ Resection margins } \\
\hline R0 & $41(82)$ \\
\hline $\mathrm{R} 1$ & $8(16)$ \\
\hline $\mathrm{R} 2$ & $1(2)$ \\
\hline Missing data & 6 \\
\hline Laboratory variables & $n(\%)$ \\
\hline \multicolumn{2}{|l|}{ Serum creatinine $(\mu \mathrm{mol} / \mathrm{L})$} \\
\hline Median (IQR) & $98(77-120)$ \\
\hline Missing & $1(1.6)$ \\
\hline \multicolumn{2}{|l|}{ Hemoglobin (g/dL) } \\
\hline Median (IQR) & $12(11-13)$ \\
\hline Missing data & $1(1.6)$ \\
\hline \multicolumn{2}{|l|}{ Anemia } \\
\hline Yes & $32(51.6)$ \\
\hline No & $29(46.8)$ \\
\hline Missing data & $1(1.6)$ \\
\hline \multicolumn{2}{|l|}{ White blood cell count $\left(\mathrm{mm}^{3}\right)$} \\
\hline Median (IQR) & $7900(6200-8900)$ \\
\hline Missing & $2(3.2)$ \\
\hline \multicolumn{2}{|l|}{ Neutrophilic leukocytosis } \\
\hline Yes & $13(21)$ \\
\hline No & $46(74.2)$ \\
\hline Missing data & $3(4.8)$ \\
\hline
\end{tabular}


Table 1. Cont.

\begin{tabular}{cc}
\hline Patients Characteristics & $\boldsymbol{n ( \% )}$ \\
\hline Hypercalcemia & \\
\hline Yes & $0(0)$ \\
\hline No & $36(58)$ \\
\hline Missing data & $26(42)$ \\
\hline
\end{tabular}

ECOG/PS: Eastern Cooperative Oncology Group/Performance Status; ADL/IADL: activities of daily living/instrumental activities of daily living; CIRS-G: Cumulative Illness Rating Scale-Geriatric; MMSE: Mini Mental State Examination; GDS: Geriatric Depression Scale; BMI: body mass index; ASA: American Society of Anesthesiologists.

The G8 score was $\leq 14$ for $69 \%$ of the patients. The pre-surgical functional status was generally maintained after RC, with a PS of 0 or 1 in $81 \%$ of the patients, an ADL score of 6 out of 6 in $87 \%$, and an IADL score of 8 out of 8 in $52 \%$. Mobility was normal (timed up and go test result $\leq 20 \mathrm{~s}$ ) for $89 \%$ of the patients, and $21 \%$ of the patient had a history of falls in the previous six months. Furthermore, $72 \%$ and $85 \%$ of the patients had not lost weight in the previous six months or the previous month, respectively. The median serum albumin level was $35 \mathrm{~g} / \mathrm{L}$. The median CIRS-G score was 11 , and $54 \%$ of the patients had one or more grade 3 or 4 comorbidities. Polypharmacy was observed in $64 \%$ of the patients.

\subsection{Thirty-Day Complication and Mortality Rates}

In the 30 days following RC, 45 patients (73\%) presented at least one complication and $17(27 \%)$ did not present any complications. The total number of complications was 100 (69 non-surgical complications and 31 surgical complications; Table 2). According to the Clavien-Dindo classification, grades I and II (minor) complications were observed in 23 patients (51\%), and grade III, IV and V (major) complications were observed for $22(49 \%)$ patients, 3 of whom died. The most frequent grade was grade II (Figure 2). The 30-day mortality rate was $4 \%$.

Table 2. Post-operative complications.

\begin{tabular}{cc}
\hline Post-Operative Complications & $\boldsymbol{n} \mathbf{( \% )}$ \\
\hline Surgical complications & $31(100)$ \\
Surgical site infection & $8(25.8)$ \\
Bleeding & $0(0)$ \\
Evisceration & $7(22.6)$ \\
Occlusion & $11(35.5)$ \\
Urinary fistula & $1(3.2)$ \\
Digestive fistula & $4(12.9)$ \\
& $n(\%)$ \\
Non-surgical complications & $69(100)$ \\
Non-surgical site infection & $23(33.3)$ \\
Thromboembolic complication & $6(8.7)$ \\
Cardiovascular complication & $17(24.6)$ \\
Delirium & $8(11.6)$ \\
Pressure sores & $1(1.5)$ \\
Fall & $2(2.9)$ \\
Others & $12(17.4)$ \\
\hline
\end{tabular}




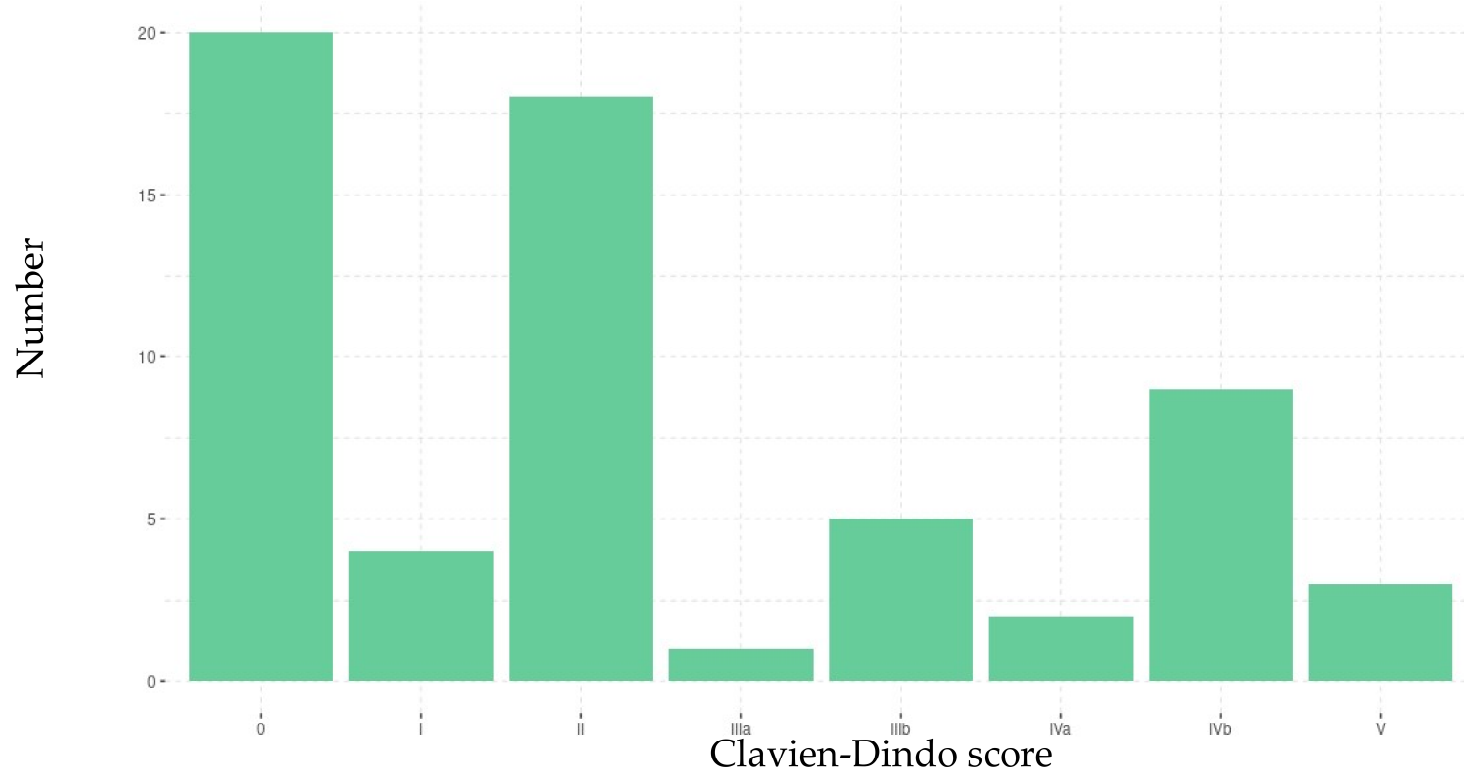

Figure 2. Severity of the patients' complications, according to the Clavien-Dindo classification.

None of the geriatric, oncologic, or laboratory variables was significative associated with the occurrence or severity of complications (Table S1).

\subsection{LOS and Discharge}

Overall, the median LOS was 18 days (interquartile range (IQR): 15-23). The LOS was significantly longer $(p=0.013)$ for patients with complications than for patients without complications, with median values of 19 days (IQR: 15-25) and 15 days (IQR: 13-16), respectively (Table $\mathrm{S} 1$ ).

Data on 30-day discharge were available for 47 patients: 25 patients (53\%) had been discharged to home, and $22(47 \%)$ were still in a rehabilitation unit. In a univariate analysis, a G8 score $\leq 14$, an ADL score $<6$, anemia, at least one CIRS-G grade 3 or 4 comorbidity, and inpatient status at the time of the pre-operative GA were significantly associated with being in a rehabilitation unit 30 days after surgery (Table 3 ).

Table 3. Univariate analyses of factors associated with the 30-day outcome (discharge or not).

\begin{tabular}{cccc}
\hline 30-Day Outcome & $\begin{array}{c}\text { Discharged to Home } \\
\boldsymbol{n} \mathbf{( \% )}\end{array}$ & $\begin{array}{c}\text { Presence in a } \\
\text { Rehabilitation Unit } \\
\boldsymbol{n} \mathbf{( \% )}\end{array}$ & $\boldsymbol{p}$ Value * \\
\hline Total & $25(53.2)$ & $22(46.8)$ & \\
\hline Median age (years) $[\mathrm{IQR}]$ & $81(76-83)$ & $83(80-84)$ & 0.07 \\
\hline Sex & & $15(68)$ & \\
\hline Male & $21(84)$ & $2(9.1)$ & \\
\hline Tobacco smoking & & $12(54.5)$ & \\
\hline Current smoker & $2(8)$ & $6(27.3)$ & 0.03 \\
\hline Former smoker & $15(60)$ & $2(9.1)$ & 0.04 \\
\hline Never-smoker & $8(32)$ & $17(94)$ & \\
\hline Missing & $0(0)$ & $6(27)$ & \\
\hline G8 $\leq 14 / 17$ & $14(64)$ & & \\
\hline Consultation & $1(4)$ & & \\
\hline Inpatient & & & \\
\hline
\end{tabular}


Table 3. Cont.

\begin{tabular}{|c|c|c|c|}
\hline 30-Day Outcome & $\begin{array}{l}\text { Discharged to Home } \\
n(\%)\end{array}$ & $\begin{array}{c}\text { Presence in a } \\
\text { Rehabilitation Unit } \\
n(\%)\end{array}$ & $p$ Value * \\
\hline Outpatient & $24(96)$ & $16(73)$ & \\
\hline Social environment & & & 1 \\
\hline Living alone & $7(28)$ & $7(32)$ & \\
\hline \multicolumn{4}{|l|}{ Functional status } \\
\hline ECOG-PS & & & 0.31 \\
\hline $0-1$ & $20(80)$ & $15(68.2)$ & \\
\hline 2 & $5(20)$ & $5(22.7)$ & \\
\hline $3-4$ & $0(0)$ & $2(9.1)$ & \\
\hline ADL score $\leq 5 / 6$ & $1(4)$ & $7(32)$ & 0.02 \\
\hline IADL score $\leq 7 / 8$ & $12(48)$ & $11(50)$ & 1 \\
\hline \multicolumn{4}{|l|}{ Mobility } \\
\hline Falls in the previous 6 months & $3(12)$ & $7(32)$ & 0.15 \\
\hline Timed up and go test $\leq 20 \mathrm{~s}$ & $22(88)$ & $15(68.2)$ & 0.64 \\
\hline \multicolumn{4}{|l|}{ Nutritional status } \\
\hline Weight loss in the last 1 month & $3(12)$ & $4(18.2)$ & 0.69 \\
\hline in the last 6 months & $4(16)$ & $6(27.3)$ & 0.47 \\
\hline $\begin{array}{l}\text { Median albuminemia }(\mathrm{g} / \mathrm{L}) \\
\text { (IQR) }\end{array}$ & $37(24-38)$ & $34(22-42)$ & 0.51 \\
\hline BMI (kg.m2) & & & 0.36 \\
\hline$<21$ & $5(20)$ & $6(27.3)$ & \\
\hline $21-25$ & $5(20)$ & $6(27.3)$ & \\
\hline $25-30$ & $14(56)$ & $7(32)$ & \\
\hline$>30$ & $1(4)$ & $3(13.5)$ & \\
\hline $\begin{array}{c}\text { Cognitive impairment (MMSE } \\
\text { score }<24 / 30 \text { ) }\end{array}$ & $2(8)$ & $4(18.2)$ & 0.4 \\
\hline Missing & $4(16)$ & $3(13.6)$ & \\
\hline $\begin{array}{l}\text { Depressive disorder (Mini-GDS } \\
\text { score } \geq 1 / 4 \text { ) }\end{array}$ & $3(12)$ & $6(27.3)$ & 0.26 \\
\hline Missing & $3(12)$ & $3(13.6)$ & \\
\hline $\begin{array}{c}\text { Comorbidity, } \geq 1 \text { grade } 3-4, \\
\text { CIRS-G }\end{array}$ & $9(36)$ & 17 (77.3) & 0.007 \\
\hline Missing & $2(8)$ & $1(4.5)$ & \\
\hline $\begin{array}{c}\text { Polypharmacy ( }>4 \text { drugs } \\
\text { per day) }\end{array}$ & $18(72)$ & $14(63.6)$ & 0.34 \\
\hline \multicolumn{4}{|l|}{ Sensory impairment } \\
\hline Eyesight & $4(16)$ & $2(9.1)$ & 0.67 \\
\hline Hearing & $10(40)$ & $11(50)$ & 0.56 \\
\hline Anemia & $8(32)$ & $15(68)$ & 0.02 \\
\hline Hypercalcemia & $0(0)$ & $0(0)$ & 1 \\
\hline
\end{tabular}


Table 3. Cont.

\begin{tabular}{lccc}
\hline 30-Day Outcome & $\begin{array}{c}\text { Discharged to Home } \\
\boldsymbol{n} \mathbf{( \% )}\end{array}$ & $\begin{array}{c}\text { Presence in a } \\
\text { Rehabilitation Unit } \\
\boldsymbol{n} \mathbf{( \% )}\end{array}$ & $\boldsymbol{p}$ Value * \\
\hline Neutrophilic leukocytosis & $4(16)$ & $5(22.7)$ & 0.71 \\
\hline Missing & $1(4)$ & $1(4.6)$ & 0.09 \\
\hline Median LOS (IQR) & $17(15-20)$ & $21(15-33)$ & \\
\hline $\begin{array}{l}\text { ECOG/PS: Eastern Cooperative Oncology Group/Performance Status; ADL/IADL: Activities of Daily Liv- } \\
\text { ing/Instrumental Activities of Daily Living; CIRS-G: Cumulative Illness Rating Scale-Geriatric; MMSE: Mini }\end{array}$ \\
$\begin{array}{l}\text { Mental State Examination; GDS: Geriatric Depression Scale; BMI: body mass index; LOS: length of hospital stay. } \\
\text { * Fisher's exact test for categorical variables and Wilcoxon's rank sum tests for continuous variables. }\end{array}$
\end{tabular}

\section{Discussion}

In the present study, RC after a GA was associated with a high 30-day complication rate (73\%). Half of these complications were major, according to the Clavien-Dindo classification. Patients with complications had a longer LOS, and almost half the patients were still in a rehabilitation unit 30 days after surgery. None of the oncologic, GA-related, or laboratory parameters were associated with complications.

The 30-day complication rate of $73 \%$ was slightly higher than that recorded for patients of all ages after RC. However, the proportion of our patients with major complications was markedly higher than in the literature. In the large MSKCC prospective cohort ( $n=1142$; median age: 68$)$, the 30 -day complication rate was $58 \%$ overall but only $18 \%$ when considering major complications [12]. Our data are also consistent with Berneking et al.'s reported value of $86 \%$ overall and $33 \%$ for major complications (according to the ClavienDindo classification) in a group of 43 octogenarians [13].

Advanced age (especially after 80 ) is associated with an elevated risk (by up a factor of 5 vs. younger patients) of postoperative death [4]. In our study, the mortality rate was twice as high as in all-age population studies (2-3\%). However, our study population was strongly selected; the GA excluded very frail patients for whom RC was not indicated.

We did not find any geriatric, oncologic, or laboratory variables associated with morbidity and mortality; this was probably due to the small number of patients in our study and thus a lack of statistical power. A recent study by Chesnut et al. found that patients aged 75 and over with impaired domains in a pre-operative electronic rapid fitness assessment (timed up and go test, cognitive function, social activity, distress, and polypharmacy) were more likely to (i) attend the emergency department, (ii) be admitted to an intensive care unit, and (iii) experience major (Clavien-Dindo grade III-V) complications after RC [14].

In our study, the median LOS stay was 18 days overall and was longer in patients with complications (19 days vs. 15 days in patients without complications). This LOS is twice as long as in the general population (8-11 days) [15] and emphasizes the association between frailty and a longer LOS [16]. Comorbidities, a low albumin level, male sex, and older age are also known to increase the LOS after cancer surgery [17-19]. In our study, all the patients were treated in high-volume centers; according to the literature data, a high number of urologic cancer operations is associated with a lower risk of complications, a shorter LOS, and a lower mortality rate [2].

Half of our study participants were still in a rehabilitation unit 30 days after RC. This rate is very high, given that the value in an all-age population of patients discharged to a care facility or a rehabilitation unit after RC is around 15\% [20]. This difference might reflect a major, prolonged loss of autonomy after RC in our geriatric population. Indeed, Murray et al. showed that patients who needed a care facility after RC had impaired ADL [21].

Factors associated with maintenance in a rehabilitation unit 30 days after $\mathrm{RC}$ were a G8 $\leq 14$, loss of autonomy for ADL, anemia, severe comorbidities on the CIRS-G, and an inpatient GA. Chesnut et al. found that patients with PS, ADL, IADL, or TUG impairments, falls in the past year, low social activity, weight loss, and self-reported depression were 
less likely to be discharged to home after RC [14]. Pearl et al. showed that frail patients (according to the $\mathrm{mFI}$ ) had a 2.33-fold greater risk of non-home discharge, and that the latter risk was even higher for patients with a major in-hospital complication [16].

Osterman et al. performed the only study to have included a GA before RC and at various times during 12 months of follow-up [22]. The researchers evaluated recovery in 80 patients aged 70 and over, in comparison to younger patients. An impairment in physical function was defined by an impairment in at least one of the following outcomes: PS, the IADL score, the TUG test, falls, or the Medical Outcomes Study Physical Health survey. At one month, both age groups had showed a worsening in physical function, but the decline was greater in the over-70 group: more than $90 \%$ of the patients had at least one impairment in physical function. At 3 months, both groups had returned to baseline levels of physical health, quality of life, and social activities. In Osterman et al.'s study, 5\% of the patients were discharged to a care facility.

With a view to reducing post-RC complications, guidelines on enhanced recovery programs have been published [23]. It has been reported that multidisciplinary geriatric patient management by surgeons, anesthesiologists, and geriatricians with direct control over medical issues during the post-operative period is associated with a significant reduction in 90-day postoperative mortality among older patients with cancer [24].

The present study had some limitations. Firstly, there is a selection bias due to the low incidence of patients included and receiving pre-operative GA. One explanation is that the ELCAPA cohort did not open at the same time in all the hospitals (initially monocentric cohort) and GA was not at first able to assess patients in all tumor boards. Another explanation is that frailty, using G8 or other tools, was not systematically used by urologists. Additionally, our cohort did not capture fit patients receiving surgery with no GA or those declined or refusing surgery or receiving radiation therapy. Therefore, our results cannot be extrapolated to the population of older patients undergoing RC in general. Secondly, data on post-operative complications were collected retrospectively from hospital reports, and so some complications might have been missed-especially delirium or falls that are specific to geriatric patients. However, the main strength of our study was the administration of a standardized, prospective GA to all our patients in high-volume cancer surgery centers.

\section{Conclusions}

Older patients selected for RC after a GA had a high 30-day complication rate. Over half the patients were still in a rehabilitation unit 30 days after RC.

Early, long-term, multidisciplinary patient management might help to slow functional decline.

Before RC, older adults should be informed of the surgery's impact on functional status and likelihood of prolonged hospitalization, especially frail patients. Further research is needed to determine which older patients are at risk of a prolonged loss of functional status after RC.

Supplementary Materials: The following are available online at https://www.mdpi.com/article/ 10.3390/cancers13236010/s1, Table S1: univaried analysis of 30-day postoperative complications. (A) no complications vs. complications. (B) minor complications (Clavien-Dindo grades I and II) vs. major complications (Clavien-Dindo grades III, IV and V).

Author Contributions: Study conception, R.G. and E.P.; data acquisition, L.S.; statistical analysis, R.V. and F.C.-P.; manuscript writing, R.G. and L.S. wrote the initial draft of the article, to which all the authors contributed subsequently; manuscript review, J.P., S.M., C.C., D.V., P.M.-A., M.B., A.M., T.C., F.C.-P., P.C. and E.P. All authors have read and agreed to the published version of the manuscript.

Funding: The ELCAPA study was funded by a grant [RINC4] from the French National Cancer Institute (Institut National du Cancer, INCa), Canceropôle Ile-de-France, and Gerontopôle Ile-deFrance (Gérond'if). The funders did not have any role in the design and conduct of the study; 
collection, management, analysis, and interpretation of the data; preparation, review, and approval of the manuscript; or decision to submit the manuscript for publication.

Institutional Review Board Statement: The study was conducted according to the guidelines of the Declaration of Helsinki and approved by the Ethics Committee CPP Ile-de-France I, Paris, France; reference: 2019 mai-MS121 (14 May 2019).

Informed Consent Statement: Informed consent was obtained from all subjects involved in the study.

Data Availability Statement: Restrictions apply to the availability of these data. Data was obtained from the ELCAPA Study Group and are available from the corresponding author with the permission of the ELCAPA Study Group investigators.

Acknowledgments: The ELCAPA Study Group consists of geriatricians (Amelie Aregui, Melany Baron, Mickaël Bringuier, Eric Bouvard, Philippe Caillet, Gaelle Cosqueric, Lola Corsin, Tristan Cudennec, Anne Chahwakilian, Amina Djender, Eric Dupuydupin, Nargess Ebadi, Virginie FosseyDiaz, Romain Geiss, Mathilde Gisselbrecht, Goldstein, Béatrice Gonzalez, Marie Laurent, Julien Leguen, Madeleine Lefevre, Celine Lazarovici-Nagera, Emmanuelle Lorisson, Josephine Massias, Soraya Mebarki, Galdric Orvoen, Frédéric Pamoukdjian, Anne-Laure Scain, Godelieve Rochette de Lempdes, Florence Rollot-Trad, Gwenaëlle Varnier, Hélène Vincent, Elena Paillaud, Agathe RaynaudSimon), oncologists (Pascaline Boudou-Rouquette, Etienne Brain, Stéphane Culine, Maxime Frelaut, Djamel Ghebriou, Joseph Gligorov, Stéphane Henault Daniel Lopez-Trabada-Ataz, Olivier Mir, Christophe Tournigand), digestive oncologist (Thomas Aparicio), gynaecological oncologist (Cyril Touboul), radiation oncologist (Jean-Léon Lagrange), nurses (Stephanie Benyahia, Sadia Bonhomme, Alzira Mota, Gwadlys Philocles, Corinne Ouakinine), epidemiologists (Etienne Audureau, Sylvie Bastuji-Garin and Florence Canouï-Poitrine), medical biologist (Marie-Anne Loriot), pharmacist (Pierre-André Natella), biostatistician (Claudia Martinez-Tapia), clinical-research medical doctor (Nicoleta Reinald), clinical-research nurse (Sandrine Rello, Melanie Lafage), data manager (Mylène Allain, Clélia Chambraud), and clinical research assistants (Aurélie Baudin, Margot Bobin, Johanna Canovas, Sabrina Chaoui, Lina Iratni, Sonia Garrigou, Sandrine Lacour, Helène Mabungu, Laure Morisset, Besma Saadaoui).

Conflicts of Interest: The authors declare that they have no conflict of interest related to this work.

\section{Abbreviations}

$\begin{array}{ll}\text { ADL } & \text { activities of daily living } \\ \text { ASA } & \text { American Society of Anesthesiology } \\ \text { BMI } & \text { body mass index } \\ \text { CIRS-G } & \text { Cumulative Illness Rating Scale-Geriatric } \\ \text { GA } & \text { geriatric assessment } \\ \text { IADL } & \text { instrumental activities of daily living } \\ \text { LOS } & \text { length of hospital stay } \\ \text { mFI } & \text { modified frailty index } \\ \text { MIBC } & \text { muscle-invasive bladder cancer } \\ \text { Mini-GDS } & \text { Mini-Geriatric Depression Scale } \\ \text { MMSE } & \text { Mini Mental State Examination } \\ \text { MNA } & \text { Mini Nutritional Assessment } \\ \text { PS } & \text { performance status } \\ \text { RC } & \text { radical cystectomy } \\ \text { TUG } & \text { timed up and go test }\end{array}$

\section{References}

1. National Cancer Institute-SEER: Cancer Stat Facts: Bladder Cancer. Available online: https://seer.cancer.gov/statfacts/html/ urinb.html (accessed on 2 July 2021).

2. Witjes, J.A.; Bruins, H.M.; Cathomas, R.; Compérat, E.M.; Cowan, N.C.; Gakis, G.; Hernández, V.; Espinós, E.L.; Lorch, A.; Neuzillet, Y.; et al. European Association of Urology Guidelines on Muscle-invasive and Meta-static Bladder Cancer: Summary of the 2020 Guidelines. Eur. Urol. 2021, 79, 82.

3. Noon, A.; Albertsen, P.C.; Thomas, F.; Rosario, D.J.; Catto, J.W.F. Competing mortality in patients diagnosed with bladder cancer: Evidence of undertreatment in the elderly and female patients. Br. J. Cancer 2013, 108, 1534-1540. 
4. Fonteyne, V.; Ost, P.; Bellmunt, J.; Droz, J.P.; Mongiat-Artus, P.; Inman, B.; Paillaud, E.; Saad, F.; Ploussard, G. Curative Treatment for Muscle Invasive Bladder Cancer in Elderly Patients: A Sys-tematic Review. Eur. Urol. 2018, 73, 40.

5. Liberman, D.; Lughezzani, G.; Sun, M.; Alasker, A.; Thuret, R.; Abdollah, F.; Budaus, L.; Widmer, H.; Graefen, M.; Montorsi, F.; et al. Perioperative mortality is significantly greater in septuagenarian and octoge-narian patients treated with radical cystectomy for urothelial carcinoma of the bladder. Urology 2011, 77, 660.

6. Garg, T.; Young, A.J.; Kost, K.A.; Danella, J.F.; Larson, S.; Nielsen, M.E.; Kirchner, H.L. Burden of Multiple Chronic Conditions among Patients with Urological Cancer. J. Urol. 2018, 199, 543.

7. Froehner, M.; Koch, R.; Hübler, M.; Heberling, U.; Novotny, V.; Zastrow, S.; Hakenberg, O.W.; Wirth, M.P. Predicting 90-day and long-term mortality in octogenarians undergoing radical cystectomy. BMC Urol. 2018, 18, 91.

8. Haren, A.; Lal, R.; Walker, D.; Nair, R.; Partridge, J.; Dhesi, J. Frailty assessment in older urological patients prior to surgery: A systematic review and narrative synthesis. Ther. Adv. Urol. 2020, 12, 1756287220916614.

9. Mottet, N.; Ribal, M.J.; Boyle, H.; De Santis, M.; Caillet, P.; Choudhury, A.; Garg, T.; Nielsen, M.; Wüthrich, P.; Gust, K.M.; et al. Management of bladder cancer in older patients: Position paper of a SIOG Task Force. J. Geriatr. Oncol. 2020, $11,1043$.

10. Mohile, S.G.; Dale, W.; Somerfield, M.R.; Schonberg, M.A.; Boyd, C.M.; Burhenn, P.; Canin, B.; Cohen, H.J.; Holmes, H.M.; Hopkins, J.O.; et al. Practical Assessment and Management of Vulnerabilities in Older Patients Receiving Chemotherapy: ASCO Guideline for Geriatric Oncology. J. Clin. Oncol. 2018, 36, 2326.

11. Caillet, P.; Canoui-Poitrine, F.; Vouriot, J.; Berle, M.; Reinald, N.; Krypciak, S.; Bastuji-Garin, S.; Culine, S.; Paillaud, E. Comprehensive Geriatric Assessment in the Decision-Making Process in Elderly Patients With Cancer: ELCAPA Study. J. Clin. Oncol. 2011, 29, 3636-3642.

12. Shabsigh, A.; Korets, R.; Vora, K.C.; Brooks, C.M.; Cronin, A.M.; Savage, C.; Raj, G.; Bochner, B.; Dalbagni, G.; Herr, H.W.; et al. Defining Early Morbidity of Radical Cystectomy for Patients with Bladder Cancer Using a Standardized Reporting Methodology. Eur. Urol. 2009, 55, 164-176.

13. Berneking, A.D.; Rosevear, H.M.; Askeland, E.J.; Newton, M.R.; O’Donnell, M.A.; Brown, J.A. Morbidity and mortality of octogenarians following open radical cys-tectomy using a standardized reporting system. Can. J. Urol. 2013, $20,6826$.

14. Chesnut, G.T.; Tin, A.L.; Sjoberg, D.D.; Jang, B.; Benfante, N.; Sarraf, S.; Herr, H.; Donat, S.M.; Dalbagni, G.; Bochner, B.; et al. Electronic Rapid Fitness Assessment Identifies Factors Associated with Adverse Early Postoperative Outcomes following Radical Cystectomy. J. Urol. 2021, 205, 400.

15. Kim, S.P.; Shah, N.D.; Karnes, R.J.; Weight, C.; Frank, I.; Moriarty, J.; Han, L.C.; Borah, B.; Tollefson, M.K.; Boorjian, S.A. The Implications of Hospital Acquired Adverse Events on Mortality, Length of Stay and Costs for Patients Undergoing Radical Cystectomy for Bladder Cancer. J. Urol. 2012, 187, 2011-2017.

16. Pearl, J.A.; Patil, D.; Filson, C.; Arya, S.; Alemozaffar, M.; Master, V.A.; Ogan, K. Patient Frailty and Discharge Disposition Following Radical Cystectomy. Clin. Genitourin. Cancer 2017, 15, e615-e621.

17. Bhalla, R.G.; Wang, L.; Chang, S.S.; Tyson, M.D. Association between Preoperative Albumin Levels and Length of Stay after Radical Cystectomy. J. Urol. 2017, 198, 1039.

18. Cárdenas-Turanzas, M.; Cooksley, C.; Kamat, A.M.; Pettaway, C.A.; Elting, L.S. Gender and age differences in blood utilization and length of stay in radical cystectomy: A population-based study. Int. Urol. Nephrol. 2008, 40, 893-899.

19. Pietzak, E.J.; Hwang, W.-T.; Malkowicz, S.B.; Guzzo, T.J. Factors Influencing the Length of Stay after Radical Cystectomy: Implications for Cancer Care and Perioperative Management. Ann. Surg. Oncol. 2014, 21, 4383-4389.

20. Taub, D.A.; Dunn, R.L.; Miller, D.C.; Wei, J.T.; Hollenbeck, B.K. Discharge Practice Patterns Following Cystectomy for Bladder Cancer: Evidence for the Shifting of the Burden of Care. J. Urol. 2006, 176, 2612-2618.

21. Murray, K.S.; Prunty, M.; Henderson, A.; Haden, T.; Pokala, N.; Ge, B.; Wakefield, M.; Petroski, G.F.; Mehr, D.R.; Kruse, R.L. Functional Status in Patients Requiring Nursing Home Stay After Radical Cystectomy. Urology 2018, 121, $39-43$.

22. Osterman, C.K.; Deal, A.M.; McCloskey, H.; Nyrop, K.A.; Bjurlin, M.A.; Tan, H.-J.; Nielsen, M.E.; Milowsky, M.I.; Muss, H.B.; Smith, A.B. Impairment and Longitudinal Recovery of Older Adults Treated with Radical Cystectomy for Muscle Invasive Bladder Cancer. J. Urol. 2021, 205, 94-99.

23. Poinas, G.; Blache, J.L.; Kassab-Chahmi, D.; Evrard, P.L.; Artus, P.M.; Alfonsi, P.; Rébillard, X.; Beaussier, M.; Cerantola, Y.; Coloby, P.; et al. Short version of recommendations for enhanced recovery program (ERP) for cystectomy: Technical measures. Prog. Urol. 2019, 29, 63.

24. Shahrokni, A.; Tin, A.L.; Sarraf, S.; Alexander, K.; Sun, S.; Kim, S.J.; McMillan, S.; Yulico, H.; Amirnia, F.; Downey, R.J.; et al. Association of Geriatric Comanagement and 90-Day Postoperative Mortality Among Patients Aged 75 Years and Older With Cancer. JAMA Netw. Open 2020, 3, e209265. 